\title{
Engineers and planners: sustainable water management alliances
}

1 Karen Potter MSC, MCD

PhD Researcher, Department of Civic Design, School of Environmental Sciences, University of Liverpool, UK

2 Sarah Ward BSC, MRes, PhD, CEnv, MCIWEM, AHEA Associate Research Fellow, Centre for Water Systems, College of Engineering, Mathematics and Physical Sciences, University of Exeter, UK

3 David Shaw BA, PhD

Professor, Department of Civic Design, School of Environmental Sciences, University of Liverpool, UK

4 Neil Macdonald MSc, PhD

Lecturer, Department of Geography, School of Environmental Sciences, University of Liverpool, UK
5 Iain White $B A, M T P L, M T C P, P h D$

Lecturer, Planning and Landscape, School of Environment and Development, University of Manchester, UK

6 Thomas Fischer PhD

Professor, Department of Civic Design, School of Environmental Sciences, University of Liverpool, UK

7 David Butler MSc, DIC, PhD, CEng, CEnv, FICE, FCIWEM, FHEA Professor, Centre for Water Systems, College of Engineering, Mathematics and Physical Sciences, University of Exeter, UK

8 Richard Kellagher MSC, CEng, MICE, MCIWEM Technical Director, HR Wallingford, Oxon, UK


In the future, increasing pressure will inevitably be placed on the spatial planning system to improve its consideration of water management issues. Emerging challenges include designing for climatic extremes, reducing flood risk, managing increasingly scarce water resources and improving water quality. These issues need to be balanced with a range of other spatial planning priorities and objectives, including meeting new housing needs, facilitating economic growth, and creating and maintaining quality places. The sheer complexity of the issues surrounding water management and the impacts upon spatial planning mean that partnership working is essential to achieve an integrated approach. Planners need the expertise, and crucially the understanding, of engineers and hydrologists. However, there can be considerable misunderstanding and miscommunication between disciplines, often concerning the institutional context in which the various parties operate. A plethora of policies, tools and assessments exist, which can make integrated water management an overwhelming prospect for the planner. This paper attempts to identify and address some of the issues faced, as well as examining how planners embed hydrological issues in decision making and how engineers could better facilitate this.

\section{In the shallows of institutional change}

From the 1990s onwards there have been significant changes in the framing and definition of water sector legislation, policy and guidelines in the UK. Emergent environmental issues and associated triggering events including sustainability and climate change, water quality concerns, droughts and catastrophic flood events have heightened awareness of water issues and raised them up the political agenda. The concept of 'integrated sustainable water management' has emerged, coupled with a reconfiguration of responsibilities and roles. 
Engineering Sustainability

Volume 164 Issue ES4
Engineers and planners:

sustainable water management

alliances

Potter, Ward, Shaw et al.
Whereas originally responsibility for water management rested largely with engineers in state environmental policy departments and agencies, this arrangement has been transformed into a more open multi-disciplinary field with a wide range of stakeholders from the public, private and third sector ('third sector' here meaning non-profit, non-governmental organisations, e.g. charitable organisations). The new policy steer is for shared responsibility and optimised coordination between water managers and neighbouring policy domains (Leroy and Arts, 2006) (see Table 1).

Within this period, issues surrounding water, planning and development have emerged as particularly critical. Unfortunately, this development in understanding has been gained through bitter experience. During the past two decades, droughts (defined in a variety of ways, see Hannaford et al. (2010) for further information) have occurred in areas of the UK, notably the severe hydrological drought of 1995 which affected mainly the north and the west of the country (POST, 1995). Future projections suggest that drought frequency and severity will increase in most regions by 2070 to 2100 , particularly in the south and east of the country (Fowler and Kilsby, 2004). The HM Treasury-sponsored Barker Report on housing supply (Barker, 2004), identified significant additional water resource needs in the south and east of England, although there were no proposed water supply solutions to meet the needs of the high projected housing growth figures (ICE, 2006). (It should be noted that there is an ongoing debate as to the appropriate scale of future housing building programmes, although indications suggest that house building rates are significantly down to 98000 per annum compared with 168000 per annum in 2007/8. What the scale of the latent or pent-up demand actually is remains open to conjecture, but new housing building will be required and this demand remains predominantly in the SE of England.) The planning system has also been heavily implicated in areas that have experienced flood risk problems; for instance the dramatic events in the 1990s and turn of the century at Boscastle and Carlisle highlighted the cumulative impact of land drainage, urbanisation and river regulation over the previous decades (Blackwell and Maltby, 2005; Ostaficzuk and Ostrowski, 2003). In 2004 there were an estimated 1.74 million properties at risk from fluvial and coastal inundation, with approximately 80000 homes at risk from intra-urban flooding (Evans et al., 2004). In the summer of 2007 flood events also affected large parts of the country outside of these areas, adding the perception of risk from surface water and inadequate drainage to that of traditional flood sources (Pitt, 2007). The most recent figures suggest that 3.8 million properties in England may currently be at risk of flooding from surface water (EA, 2009a) - an enormous increase within the space of 5 years (although the validity of this projection is subject to conjecture and figures could be higher). Water has traditionally been within the remit of engineers and hydrologists, as there has been a perception it can be accurately quantified and, therefore, to some extent, controlled. However, the uncertainty in water management this changing situation has generated and the increased understanding of the uncertainty in risk management, have revealed the need to be more precautionary and include a wider variety of stakeholders in decisions. The lack of surety essentially argues for a shift towards a more collaborative approach incorporating both a range of skill sets from the professional sector and the views of communities who will be expected to live with the risk (White, 2010).

This heightened awareness of the complexities in the relationship between water management and new development places considerable emphasis on the spatial planner as a key stakeholder in the successful delivery of a new integrated approach to sustainable water management (CLG, 2009). For instance, more effective treatment of wastewater and surface water pollution and changing the mind-set that rainfall runoff is also a potential asset, combined with an appreciation that existing properties are under unavoidable threat from flood risk. Described as the most substantial piece of EC water legislation to date, the river-basin management approach of the water framework directive (WFD) also stresses the interrelationship between water management and land use, through which the need for water issues to be considered at local and regional spatial planning levels has been made

Making Space for Water (Defra, 2004) - holistic, catchment approach, involving all stakeholders

Water Efficiency in New Buildings (CLG and Defra, 2006) - highlighting the need for bottom-up water efficiency

Groundwater Protection: Policy and Practice (EA, 2006) - providing a framework to work with developers, planners, other agencies and those working in industry and agriculture

Future Water (Defra, 2008) - considering mitigation and adaptation measures to ensure resilience in response to climate change Water for People and the Environment (EA, 2009b) - working together to make sure there is enough water for people and the environment

Flood and Water Management Act (Defra, 2010) - clarifying responsibilities for new approaches, such as sustainable drainage systems (SUDS) 
Engineering Sustainability

Volume 164 Issue ES4
Engineers and planners:

sustainable water management

alliances

Potter, Ward, Shaw et al. explicit (CLG, 2009; Moss and Monstadt, 2007). The progressive responses of engineers and hydrologists (and other key stakeholders), for example water cycle studies (EA, 2009c), sustainable drainage, rain water harvesting, blue belts and floodplain restoration (land that is intended to flood), all require mainstreaming in planners' strategic policy making and in detailed decisions on specific planning applications.

A straightforward problem and response? Unfortunately not. Spatial planners have been accused of evading wider responsibilities regarding integrated water management; the relationship between planning and flood risk management for instance being likened to a 'fish out of water' (Howe and White, 2004). Although controls over floodplain development have been tightened with the introduction of Planning Policy Statement 25 - Development and Flood Risk (PPS 25) (CLG, 2006), any innovative responses, as listed above, are weak. In short, although the water policy framework has reacted, and continues to react swiftly in response to evolving shifts in understanding, the common perception is that planners still need to respond in kind.

There are a number of problems, including a limited understanding of the planning process by engineers and water managers, that present barriers to the implementation of more sustainable water management practices, as will be described below.

\section{Planners - like a 'fish out of water' or 'more fish to fry'?}

As part of the former Labour Government's planning reform agenda, which was enshrined in legislation in 2004 and 2008, planning was given a central role in coordinating and enabling the delivery of sustainable communities and world-class places (CLG, 2004, 2009). The language of planning was transformed. We now talk about 'spatial planning' rather than land use planning. The new 'spatial planning' regime goes beyond traditional land use planning to bring together and integrate policies for the development and use of land with other policies and programmes, which influence the nature of places and how they can function (CLG, 2006). Development control with its negative regulatory nuances has been reimaged as 'development management' with connotations of being more facilitating and enabling. For instance, through the concept of 'total place' (HM Treasury and CLG, 2010), the focus is on all agencies in a particular locality to work together in partnership to deliver better public services more efficiently and effectively and to meet the specific needs of their communities. Spatial planners have the responsibility in managing and coordinating the activities of this wide variety of public and private sector actors and agencies in order to create, maintain and enhance 'places where people want to live' (ODPM, 2002: p. 5). With the new coalition government in power from 2010, the language has changed and the planning system will be reformed. However, the ideas of 'big society' and 'localism' bring with them further notions of collective and integrated action to meet locally determined needs and aspirations.

Yet, in addressing the coordinated delivery of sustainable communities and 'total place', the requirement to work in partnership with engineers/hydrologists and facilitate the delivery of integrated sustainable water management sits on the planner's priority list alongside a plethora of other environmental, social and economic issues and concerns. Together with decisions on the location of new communities, the future of cities and the use of land for food production and leisure, decisions are also required in transport investment, marine issues, health, energy generation and distribution (RTPI, 2010) and the latest example, 'planning and terrorism' - each and every one of these issues and concerns being as complex and convoluted as the delivery of integrated water management. Many are also commonly perceived to be underrepresented and sidelined by spatial planners who are alleged to place their main focus on economic development (Therivel et al., 2009).

The complexity described so far relates to 'horizontal' activity - that is, across the variety of different sectors and policy domains. Added to the planner's task, integration is also required 'vertically' - that is, between different tiers of governance regime, from the national through the regional to the local level and between all of the different stakeholders who will be required to collaborate in order to deliver projects at site level. The complex interaction of these vertical and some horizontal elements of the spatial planning system is illustrated diagrammatically in Figure 1.

Similarly, another challenge facing the new planning regime at the horizontal level is dealing with the 'impermeability' of administrative boundaries, to deal with cross-boundary issues and the fact that different administrative boundaries for different sectoral regimes rarely coincide. In this context, river catchment boundaries (and the WFD river basin management approach) frequently sit oddly within statutory spatial planning levels.

As Shaw (2006) understates, 'in an increasingly complex and interconnected world, spatial plans should not be developed in isolated, functional or spatial silos. It may be easy to have such ideas, but much more difficult to operationalise them' (p. 18). If spatial planners are to live up to their potential and responsibilities in facilitating the delivery of integrated, sustainable water management, then a close and effective collaborative partnership with engineering colleagues is of vital importance. The expertise necessary to understand the complexities of the issues cannot always reside in a single head 




Local development frameworks - Local transport plans - Waste management strategies



Figure 1. The complex network of vertical and some horizontal interactions involved in integrating planning and sustainable water management

(Thomson, 2009). The expertise of engineers and hydrologists (together with other key stakeholders) is required to ensure that the appropriate issues and responses, relating to the particular space, are fully integrated into both policy and decision-making processes.

Such an engagement with spatial planning can be problematic however. The complex and dynamic nature of the planning system may itself be an impediment to interdisciplinary understanding and place an onus on planners to inform other professions as to their processes and constraints. From the planner's perspective, if engineers could develop their understanding and engage early and throughout the spatial planning process, this could greatly enhance and support the consideration and integration of sustainable water management into planning policy and practice.

\section{Understanding the planning process}

Policy makers have recently placed a greater emphasis on the planning policy framework that exists in a particular locality. Through 'spatial planning' the concept of a single plan has been replaced by a local development framework (LDF). The LDF consists of a portfolio of locally determined development plan documents designed to create a strategy of how a place should develop over the next 10-15 years. (It should be noted that the coalition government has started to reform the planning system, although it is not entirely clear what the new policy framework will look like. To date, regional spatial strategies (intended to provide a framework for lower-tier policy making) have been revoked.) The new system places great emphasis on plan-making processes being open, transparent and justifiable. Issues and options must be critically appraised in the light of local agendas, be evidence based, shaped by stakeholder consultation and intended to respond to local needs (Shaw and Lord, 2009). Integrated planning support instruments, such as sustainability appraisal, are aimed at aiding the evaluation of options in an open and transparent manner (Kidd and Fischer, 2007). The documents are subject to external scrutiny and are evaluated based on the concept of 'soundness'. The resultant policy framework should guide and shape specific decisions and interventions in the place-making agenda.

Key to achieving a 'sound' plan is stakeholder engagement from the beginning of plan preparation; this is often known as 'frontloading'. Frontloading involves gathering factual evidence at the start of the process and requires positive and proactive engagement by stakeholders from the outset, so that the preferred strategy in theory emerges through a rational and inclusive dialogue. In the past, various stakeholders waited until relatively late in the plan-making process before reacting negatively to proposals by objecting to sections of the plan they did not like. If the plan is to be effective in achieving water management objectives, this translates to having engineers as a key stakeholder in delivery, 'sign up to' and deliver the objectives in the plan.

In the making of place, much emphasis has recently been placed on a 'culture change', transforming the perceptions of planning and planners, including the way they work and integrate with other actors and agencies (Shaw and Lord, 2007). It is clearly up to planners to grasp the opportunity being afforded to them, to do things differently from the recent past and demonstrate how they make a positive contribution to 
Engineering Sustainability

Volume 164 Issue ES4
Engineers and planners:

sustainable water management

alliances

Potter, Ward, Shaw et al. water management (Shaw, 2006). Nevertheless, to move forward to a new form of relationship, to cooperate and take important decisions together in the delivery of integrated water management, key differences are immediately apparent in how integrated water management is viewed and valued by and between us as two key stakeholders. These complicate the fostering of a close partnership and for the differences to be overcome, an understanding of contrasting institutional context and culture must be further developed.

\section{Understanding the differences in culture and context}

For most of the twentieth century, water managers consisted of engineers and hydrologists working from a technical viewpoint within a closed policy domain of water management (Wiering and Immink, 2006). Planners on the other hand were more concerned with the pressures of population growth and ensuring there was sufficient land available to meet development needs (Cullingworth and Nadin, 2006). A more or less stable alliance was established between engineers and planners, whereby engineers focused on spatially separating water and development land in the 'battle against water'. In many cases, this comfortable institutional arrangement persists, with the mind-sets of less progressive planners and engineers proving difficult to change (Moss and Monstadt, 2007). The lack of track record for the new approaches to integrated water management leaves these engineers and planners dismissive or cautious of the new environmental discipline, their ideologies creating mechanisms of path dependency, posing significant barriers and frustrating attempts to innovate from their more progressive colleagues (Adams et al., 2004). As Moss and Monstadt (2007) note, there is mounting 'anecdotal' evidence that it is not local stakeholders who fail to appreciate recent shifts in government policy, but that they are unable to follow policy as they themselves and central government would like.

Fundamental differences are also apparent in our perspective and 'language'. Engineers are often seen to reason from tried and tested civil engineering norms and standards, based on probabilistic risk analysis, safety engineering, measurements and modelling of measures to predict the behaviour of water. Key terminology concerns peak discharges, strength and height of structures, economic damage, casualties and construction cost. Space is viewed in a quantitative way, in kilometres, volumes and cubic metres (Wiering and Immink, 2006). Often for the engineer/hydrologist the solution is not considered in terms of its connection to other planning objectives but in the reliability and confidence that can be placed in the design. By contrast, those spatial planners with awareness of water issues articulate visions of new multifunctional relationships between water and the environment, seeking links to other spatial functions and planning objectives, including housing, landscape enhancement, nature conservation, recreation, health and adaption and mitigation of climate change (encompassed in the concept of 'green infrastructure'). Spatial planners view space in a qualitative way - as a landscape, a region, a locality (Wiering and Immink, 2006).

Another difficulty relating to our evolving new relationship is that there are fundamental differences between engineers and planners in how we interpret the position of water in terms of planning principles. Although spatial planners may understand the significance and importance of the move to a more integrated, thereby sustainable approach, it does not necessarily follow that water will be given exclusive priority above the innumerable other planning needs, particularly housing and economic development. For the other partner in the relationship, the water management engineer, the consideration of water is fundamental. 'Water' is not one of many competing issues to weigh up; its consideration is seen as requiring precedence over other issues as a necessary precondition to any spatial planning activity.

Decision making and delivery is not just a matter of technical facts, it is also a matter of how water management is viewed and valued. If different agencies have varying approaches and definitions of issues, the obvious results are conflicting strategies, lack of coordination and persisting implementation deficits (Leroy and Arts, 2006). As in any healthy relationship and partnership, how do we reach an understanding and undertake the required shifts in perception?

\section{Summary and a way forward?}

Growing concerns relating to the possible impact of climate change and associated potential increases in the severity, frequency and seasonality of flooding events, water shortages and drought have generated numerous reports and policy reviews both at the national level and at a European level. There is an increasing policy demand for a more integrated and sustainable approach to water management. However, substantial differences persist between policy on paper and policy in practice. In this paper an argument has been presented for integrated partnership working between the disciplines of planning and engineering to enable a more effective delivery of the sustainable water management approach. Although policy may have undergone a step change to integrated water management, our professional partnership working has yet to fully respond in kind.

The reform and transition from a narrow land use regulatory framework towards a wider and more integrated concept of spatial planning presents difficulties in balancing conflicting and competing demands. The change in approach and challenges in integration do not only demand spatial planners adapting to new methods of working; all other stakeholders who engage with the spatial planning system also need to 
Engineering Sustainability

Volume 164 Issue ES4
Engineers and planners:

sustainable water management

alliances

Potter, Ward, Shaw et al. re-evaluate their ways of thinking and working with spatial planners (Shaw, 2006). Partnership working requires engineers and hydrologists to have an understanding of the planning system, its constraints and how to facilitate integrated sustainable responses within these constraints. Expertise is required from engineers regarding both quantitative water issues and responses (from flood management, safe and sustainable drainage and runoff, safe disposal of wastewater, securing sustainable amounts of water and water efficiency) and qualitative issues (such as restoring water-based ecological habitats and meeting requirements for higher standards of water quality). Furthermore, the planning system provides an opportunity for stakeholders in the pursuit of sustainable development (and thus readers of this journal) to integrate the plethora of water sector policies with wider social, economic and environmental objectives, including an increase in biodiversity, enhanced landscapes and increased leisure opportunities.

Success in front loading spatial plans and delivery of truly sustainable development relies on overcoming narrow approaches to ways of working and disciplinary nuances in technical language, translating knowledge to planners in a qualitative manner that they can translate, but supported by an appropriate evidence base (Macdonald et al., 2010). How do we flush out institutionalised mind-sets that frustrate aspirations and endeavours being made by progressive and innovative planners and engineers to follow government policy direction, or avoid less aware planners relying on outmoded advice and solutions?

Overcoming the level of prioritisation that water is afforded also presents a particular dilemma. How can a platform be raised where varying interests and where an evaluation of trade-offs of different development options may be achieved? Strategic environmental assessment (SEA) and environmental impact assessments (EIA) are formally required for certain plans, programmes and projects and in theory arguably could fulfil this role, if they were developed further from their current form of application (Fischer, 2007, 2010). Depending on the specific decision-making situation, these iterative instruments may be based on, for example, a roundtable approach in order to facilitate compromise (in situations that are marked by controversy and high uncertainty); or on a simple (qualitative or quantitative) analysis of consequences (in situations of broad consensus and a low degree of uncertainty) of different development paths (see Fischer et al., 2010). Engineering research with regard to the provision of such assessment tools, for regional and local planning, is being undertaken within the current 'ReVISIONS' project (ReVISIONS, 2010), one of several projects working on tools for the integration of new development infrastructure. The project is aiming to produce an integrated water-waste-transport-energy planning tool, using a multi-criteria analysis approach, so that quantitative and qualitative sustainable development indicators can be included. However, the development of such tools requires the involvement of spatial planners, to ensure they meet the needs of day-to-day planning activity (Macdonald et al., 2010). There will also be a need to collect data to increase the accurate quantification of risk, in order to determine priorities and influence the effectiveness of assessment tools. This may be an area where the two professions could profitably work together to reduce uncertainty and make better decisions.

\section{Raising a debate}

In progressing to successful planner-engineer partnerships, the current authors believe that new creative ways of working are required and perhaps a 'strategy for partnership working', aiming to facilitate understanding and operationalise all aspects of policy that cover the planning-water management arena. Therefore the primary question is, what would (or should) such a strategy look like? The following are a selection of suggested pathways and activities that, if suitably integrated, could be undertaken to consolidate the necessary interdisciplinary thinking, partnerships and dissemination. The activities are equally applicable to both disciplines, but the emphasis here is given to how engineers can become involved with planning, as a result of the situation of this paper within an engineering-facing journal.

The strategy would need to bring together institutions, departments, academics and practitioners in ways that would

(a) encourage interdisciplinary thinking, outside of disciplinary silos

(b) increase awareness of the need for interaction

(c) increase opportunities for interaction - or showcase exemplars of where this has already been undertaken

(d) increase support for interaction - not only funding but a network of expertise.

Activities that promote the above pathways could include

(a) organisation of interdisciplinary conferences, workshops and seminars (such as that held by the authors in collaboration with the British Hydrological Society, see http://pcwww.liv.ac.uk/ nim/bhs10/hydroplanning.htm for more details)

(b) encouraging and increasing the presence of the planning community at engineering-orientated water events, for example by inviting specialist presenters and guests

(c) involvement with planning networks, such as the Royal Town Planning Institute (RTPI) 'Environmental Planning and Protection Network', which has a special stream on 'Water and Marine Spatial Planning' (http:// 
Engineering Sustainability

Volume 164 Issue ES4
Engineers and planners:

sustainable water management

alliances

Potter, Ward, Shaw et al. www.rtpi.org.uk/environment_planning_and _protection_network/)

(d) introduction of 'area working groups' or a 'buddy' scheme, where planners and engineers in different organisations/institutions link together to facilitate knowledge transfer and consultation; the Chartered Institution for Water and Environmental Management (CIWEM) has recently started a 'buddy' scheme between its members and members of parliament (MPs) in order to increase knowledge exchange across the policyenvironment divide

(e) initiation of a 'water and planning' journal or magazine, or targeting of a range of suitable publications that could provide a forum for planning and engineering papers specifically oriented to planning aspects of water management

(f) increasing the visibility of existing networks highly pertinent to planning and engineering in the water environment, such as the Inter-Institutional Flood Risk Management Group (which includes ICE, RTPI and CIWEM, as well as the Royal Institute of British Architects (RIBA) and other organisations).

An important step in tackling the need for dialogue between planners and the engineering/hydrology community was taken by the multi-disciplinary research WaND project (Water Cycle Management for New Developments), from 2003 to 2008. WaND aimed to support the delivery of a more integrated and sustainable approach to water management for new developments by the provision of tools and guidelines for project design, implementation and management. As part of the project output, guidance was published that outlines the policy context and the processes involved in sustainable water cycle management focusing on why it is required and what

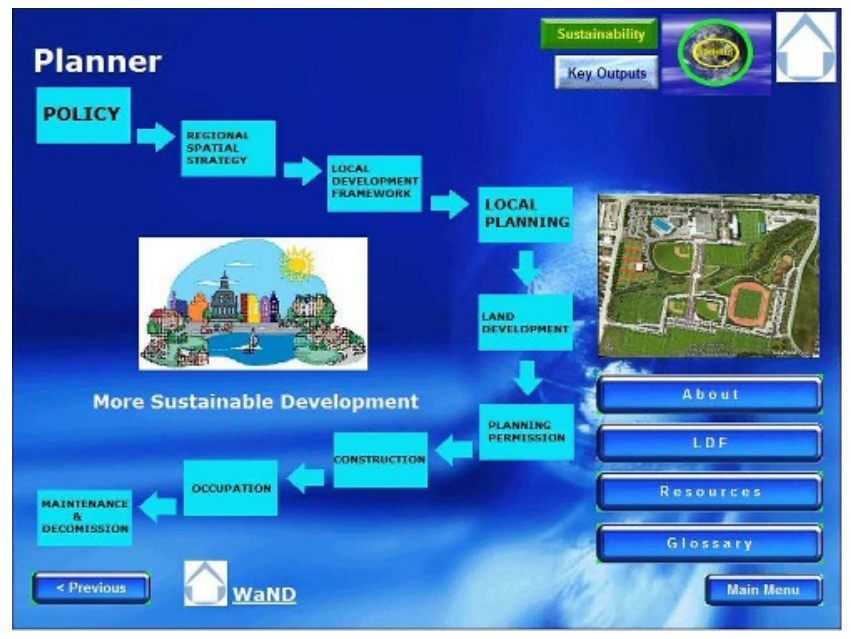

Figure 2. Planners' page of the WaND portal (Butler et al., 2010) approaches are needed for its successful planning and delivery (Butler et al., 2010). An explicit conclusion of the work was that the planning process is central in achieving sustainable water cycle management and it was recommended that water supply, wastewater disposal and surface water management are considered early in the planning process. A further deliverable from the project was the 'WaND-portal' that provided a tailored approach to searching the myriad outputs from the project from the point of view of key stakeholders, planners being a case in point (see Figure 2).

Looking to the international arena, the emergence of water sensitive urban design (WSUD) in Australia presents a possible model for the UK to aspire to. WSUD represents the integration of urban water cycle management and urban design and planning, with an aim to minimise the hydrological impacts of development upon the local environment (Urrutiaguer et al., 2010). Within the WSUD framework, water service providers work in partnership with local government (councils) and the community to form a programme team, which is involved from the start of a new development plan and aims to raise awareness and educate all parties in order to facilitate the long-term success of implemented WSUD features (Urrutiaguer et al., 2010).

These are but only a handful of possible ways in which planners and engineers can bridge the gaps in understanding, to enhance partnership working and thus facilitate the implementation of sustainable water management techniques. It is hoped this paper, composed by an interdisciplinary authorship of planners, engineers and hydrologists, will stimulate discussion and debate. If the 'battle' against water is over, planners and engineers must move forward and forge new constructive partnerships. Although recognising the myriad of guidance available for the water and planning arena, overcoming the barriers to the implementation of more sustainable water management practices can only be achieved by partnership working and the broadening of horizons that develop from interdisciplinary thinking. This culture change involves organisational structure and new methods of working, but crucially it also involves hearts and minds (Shaw, 2006).

\section{Acknowledgements}

In writing this paper the authors acknowledge the presentations and thoughts of the other speakers at the BHS National Meeting, University of Liverpool, 2010 and thank them for directly or indirectly shaping some of the content within this paper. The views expressed in this paper, however, remain those of the authors and do not necessarily reflect those of the BHS or the speakers. The other speakers at the meeting included: Dave Bayliss (Dwr Cymru Welsh Water), Matt Ellis (Environment Agency) and Francis Hesketh (TEP). 
Engineering Sustainability

Volume 164 Issue ES4
Engineers and planners:

sustainable water management

alliances

Potter, Ward, Shaw et al.

\section{REFERENCES}

Adams WM, Perrow MR and Carpenter A (2004) Conservatives and champions: river managers and the river restoration discourse in the United Kingdom. Environment and Planning A(36): 1929-1942.

Blackwell MSA and Maltby E (eds) (2005) Ecoflood Guidelines: How to Use Floodplains for Flood Risk Reduction. The Ecoflood Project, European Commission, Luxembourg.

Butler D, Memon FA, Makropoulos C, Southall A and Clark L (2010) WaND. Guidance on Water Cycle Management for New Developments. Construction Industry Research and Information Association, London, CIRIA Report C690.

CLG (Department of Communities and Local Government) (2004) Planning and Compulsory Purchase Act. The Stationery Office, London.

CLG (2006) PPS 25: Development and Flood Risk. The Stationery Office, London.

CLG (2009) World Class Places: The Government's Strategy for Improving Quality of place. The Stationery Office, London.

CLG and Defra (Department for Environment, Food and Rural Affairs) (2006) Water Efficiency in New Buildings; a Consultation Document. Communities and Local Government Publications, London, UK.

Cullingworth B and Nadin V (2006) Town and Country Planning in the UK, 14th edn. Routledge, Abingdon.

Defra (2004) Making Space for Water - Developing a New Government Strategy for Flood and Coastal Erosion Risk Management in England. Defra, London.

Defra (2008) Future Water: The Government's Water Strategy for England. CM7319. Defra, London.

Defra (2010) Flood and Water Management Act: Hansard Reports. Defra, London. See http://www.defra.gov.uk/ environment/flooding/policy/fwmb/next.htm (accessed June 2010).

EA (Environment Agency) (2006) Underground, Under Threat: Groundwater Protection: Policy and Practice. EA, Bristol.

EA (2009a) Flooding in England: A National Assessment Of Flood Risk. EA, Bristol.

EA (2009b) Water for People and the Environment: Water Resources Strategy for England and Wales. EA, Bristol.

EA (2009c) Water Cycle Study Guidance, January, vol. 4. EA, Bristol. See http://publications.environment-agency.gov. uk/pdf/GEHO0109BPFF-e-e.pdf (accessed June 2010).

Evans E, Ashley R, Hall J et al. (2004) FORESIGHT. Future Flooding, vol. 1. OST, London.

Fischer TB (2007) Theory and Practice of Strategic Environmental Assessment - Towards a More Systematic Approach. Earthscan, London (also published in Chinese by Science Press in 2008).

Fischer TB (2010) Reviewing the quality of strategic environmental assessment reports for English spatial plan core strategies. EIA Review 30(1): 62-69.
Fischer T, Dalkmann H, Lowry M and Tennøy A (2010) The dimensions and context of transport decision making. In Indicators on Environmental Sustainability in Transport (Joumard R and Gudmundson H (eds)). Inrets, Paris, pp. 83-107.

Fowler HJ and Kilsby CG (2004) Future increases in UK water resource drought projected by a regional climate model, 2004. Hydrology: Science and Practice for the 21st Century, pp. 15-21.

Hannaford J, Lloyd-Hughes B, Keef C, Parry S and Prudhomme C (2010) Examining the large-scale spatial coherence of European drought using regional indicators of precipitation and streamflow deficit. Hydrological Processes 25(7): 1146-1162. doi: 10.1002/hyp.7725.

Barker K (2004) Review of Housing Supply. Delivering Stability: Securing our Future Housing Needs. HM Treasury, London, UK. See http://webarchive.nationalarchives.gov. uk/+/http://www.hm-treasury.gov.uk/media/E/4/ barker_review_execsum_91.pdf (accessed 19/10/2011).

HM Treasury and CLG (2010) Total Place: A Whole Area Approach to Public Services. HMSO, London.

Howe J and White I (2004) Like a fish out of water: the relationship between planning and flood risk in the UK. Planning, Practice and Research 19(4): 415-425.

ICE (Institute of Civil Engineers) (2006) Policy Position Statement Water Supply and Demand. ICE, London, UK.

Kidd S and Fischer TB (2007) Towards sustainability: is integrated appraisal a step in the right direction? Environment and Planning C 25(2): 233-249.

Leroy P and Arts TB (2006) Institutional Dynamics in Environmental Governance (Arts B and Leroy P (eds)). Springer, Dordrecht, the Netherlands.

Macdonald N, Potter K and Ward S (2010) Hydrology and spatial planning. Proceedings of the 3rd International British Hydrological Society Symposium Newcastle, pp. 366-372, ISBN 1903741165.

Moss T and Monstadt J (eds) (2007) Restoring Floodplains in Europe: Policy Contexts and Project Experiences. IWA Publications, London.

ODPM (Office of the Deputy Prime Minister) (2002) Sustainable Communities: Building for the Future. ODPM, London.

Ostaficzuk S and Ostrowski M (2003) The faulty solutions of anti flood measures. Proceedings of the International Conference Towards Natural Flood Reduction Strategies, Warsaw.

Pitt M (2007) Learning Lessons from the 2007 Floods, An Independent Review by Sir Michael Pitt. Cabinet Office, London.

POST (The Parliamentary Office of Science and Technology) (1995) The 1995 Drought. POST, London, Technical Report. See http://www.parliament.uk/documents/post/ pn071.pdf (accessed 01/05/2010).

ReVISIONS (2010) ReVISIONS homepage. See http://www. regionalvisions.ac.uk/ReVISIONS/Home.aspx (accessed 01/05/2010). 
RTPI (The Royal Town Planning Institute) (2010) Shaping the Future - The RTPI Manifesto for Planning. RTPI, London.

Shaw D (2006) Culture Change and Planning Literature Review, Spatial Plans in Practice: Supporting the Reform of Local Planning. CLG, London, UK.

Shaw D and Lord A (2007) The cultural turn? Culture change and what it means for spatial planning in England. Planning Practice and Research 22(1): 63-78.

Shaw D and Lord A (2009) From land-use to 'spatial planning': reflections on the reforms of the English planning system. Town Planning Review 80(4-5): 415-436.

Therivel R, Christian G, Craig C et al. (2009) Sustainability focused impact assessment: English experiences. Impact Assessment and Project Appraisal 27(2): 155-168.
Thomson M (2009) Strategic planning and water - the Royal Town Planning Institute perspective. Proceedings of Water and Planning - Planning Guidance for Water Issues (Ciwem DAD (ed.)). University College of London, London, UK.

Urrutiaguer M, Lloyd S and Lamshed S (2010) Determining water sensitive urban design project benefits using a multi-criteria assessment tool. Water Science and Technology 61(9): 2333-2341.

White I (2010) Water and the City: Planning for a Sustainable Future. Taylor and Francis, Abingdon.

Wiering M and Immink I (2006) When water management meets spatial planning: a policy arrangements perspective. Environment and Planning C: Government and Policy 24: 423-438.

\section{WHAT DO YOU THINK?}

To discuss this paper, please email up to 500 words to the editor at journals@ice.org.uk. Your contribution will be forwarded to the author(s) for a reply and, if considered appropriate by the editorial panel, will be published as discussion in a future issue of the journal.

Proceedings journals rely entirely on contributions sent in by civil engineering professionals, academics and students. Papers should be $2000-5000$ words long (briefing papers should be 1000-2000 words long), with adequate illustrations and references. You can submit your paper online via www.icevirtuallibrary.com/content/journals, where you will also find detailed author guidelines. 